\title{
El desafío de las publicaciones científicas... cómo seguir siendo elegidas por los lectores
}

The challenge of scientific publications... how to remain chosen by readers

Las publicaciones científicas, junto con los congresos y los colegas son las "fuentes de información" que habitualmente consultan los pediatras. Esto confirma que las revistas científicas continúan siendo una fuente de información para los profesionales de la salud y siguen siendo el principal medio por el cual se publican los resultados de la investigación científico-académica. Es importante que los profesionales de la salud estén al tanto de los avances que la medicina para no quedar al margen de los mismos y aprovecharlos para su actividad asistencial. Los artículos publicados en las revistas científicas son importantes para sus lectores, por una variedad de razones, entre las que se encuentran el acceso a la investigación científica, la docencia, el hecho de mantenerse actualizado en temas de interés de la especialidad, escritura de trabajos científicos, entre otras.

Las publicaciones periódicas se han mantenido a lo largo del tiempo como uno de los métodos más reconocidos para mantenerse informado, pero el gran volumen de información científica que se publica no ayuda, ya que muchas veces el profesional de la salud queda abrumado por tanta información. La serie "How to keep up with the medical literature" publicada en el JAMA hace más de 25 años, proponía que para mantenerse al día con la literatura científica en forma eficiente y efectiva era necesario seleccionar artículos originales, ya que estos ofrecen información relevante y válida para su aplicación clínica; también los lectores debían focalizar la lectura sobre temas propios de su especialidad y por último seleccionar estudios que tuvieran un estándar lo suficientemente alto para poder garantizar la acción clínica asociada a los resultados de la investigación consultada.

En el año 2000, estalla el boom de las publicaciones científicas disponibles en la web. En ese momento se describieron una serie de "amenazas" que podían afectar a la publicación de la producción científica de las ciencias en general. Estos mitos puntualizaban que las revistas científicas no serían leídas ya que existían demasiadas publicaciones especializadas, que las revistas solo serían para los autores ya que los investigadores conocerían la información antes que apareciera publica- da y por último que las publicaciones electrónicas harían que los editores y bibliotecarios fueran obsoletos. Hoy en día existe una gran cantidad de artículos científicos disponibles en la web en comparación con hace 10 años. Se calcula que el 96\% de la revistas médicas se encuentran disponible en la web, ya que no solo está disponible lo publicado en forma reciente sino que también se puede consultar el repositorio de números anteriores por los sistemas de publicación electrónica. Archivos Argentina de Pediatría permite consultar los números anteriores de los últimos 15 años, pero algunas publicaciones como el New England Journal of Medicine poseen todos sus números disponibles en línea desde el inicio de su publicación en 1812 y el Pediatrics de igual manera desde su primer número publicado en 1948.

Archivos Argentinos de Pediatría (AAP) ha ido transformándose, a lo largo de sus más de 80 años de publicación ininterrumpida, para asegurar su lugar de preferencia como fuente de información para los pediatras e integrantes del equipo de salud dedicados al cuidado de niños y adolescentes de nuestro país y otros países de habla hispana. Este esfuerzo apunta en que $A A P$ sea una publicación con contenido interesante y de calidad, buscando abordar los temas de mayor interés que permitan la difusión del conocimiento y sean de utilidad en la tarea cotidiana de los pediatras y otros profesionales abocados al cuidado de la salud de población infantil.

Para AAP la opinión de sus lectores es importante a fin de continuar creciendo, es por eso que la encuesta realizada en el año 2009, a 1400 de nuestros lectores nos sirvió para conocer el perfil y preferencias de aquellos que nos leen para poder brindar un contenido que en cierta medida respete su preferencia. Como datos relevantes encontramos que nuestros lectores tenían preferencia a leer $A A P$ en papel, los principales motivadores para la lectura eran la búsqueda de información para su actividad profesional y la necesidad de mantenerse actualizado, y los principales temas de interés eran pediatría ambulatoria, crecimiento y desarrollo, infectología, nutrición, diagnóstico por imágenes y adolescencia. 
Recientemente, hemos publicado en http:/ / www.surveymonkey.com/s/aap_2012 una nueva encuesta que tiene como objetivo evaluar la opinión de nuestros lectores acerca del contenido de $A A P$ y también conocer el perfil y preferencias de los mismos. De esta manera podremos ver si el perfil de nuestro lectores ha variado con el correr de los años. En esta oportunidad queremos también evaluar el uso de herramientas Web 2.0 por parte de aquellos que nos leen. Las redes sociales se están perfilando como una nueva forma de comunicación entre profesionales a través de la web, más allá de las relaciones personales. Diferentes publicaciones y sociedades científicas ya utilizan las plataformas 2.0 como canal de comunicación. Nuestra revista no es ajena al uso de nuevas formas de comunicación para difundir su contenido. El servicio de subscripción electrónica a la tabla de contenidos y novedades posee más de 9200 subscritores. Hace dos años hemos creado un ca- nal de difusión en Twitter (@arch_argent_ped) que tiene mas de 550 seguidores y también divulgamos el contenido de $A A P$ a través del espacio de Facebook que la Sociedad Argentina de Pediatría posee en http:/ / www.facebook.com/soc.arg. ped con una llegada a 8000 usuarios.

Valoramos la opinión de nuestros lectores, es por eso que esperamos puedan completar la encuesta para ayudarnos a seguir brindando información de investigación científica de interés para los responsables del cuidado de la salud de recién nacidos, niños y adolescentes.

Dra. Paula Otero

Editora Asistente

Archivos Argentinos de Pediatría

http:/ /dx.doi.org/10.5546/aap.2012.370 